\title{
Scope of practice review: providers for triage and assessment of spine-related disorders
}

This article was published in the following Dove Press journal:

Journal of Multidisciplinary Healthcare

10 May 2016

Number of times this article has been viewed

\section{Omenaa Boakye' \\ Arden Birney' \\ Esther Suter' \\ Leah Adeline Phillips ${ }^{2}$ \\ Victoria YM Suen ${ }^{3}$}

'Workforce Research and Evaluation, Alberta Health Services, Calgary, ${ }^{2}$ College of Licensed Practical Nurses of Alberta, Edmonton, ${ }^{3}$ Addiction and Mental Health SCN, Alberta Health Services, Edmonton, $A B$, Canada

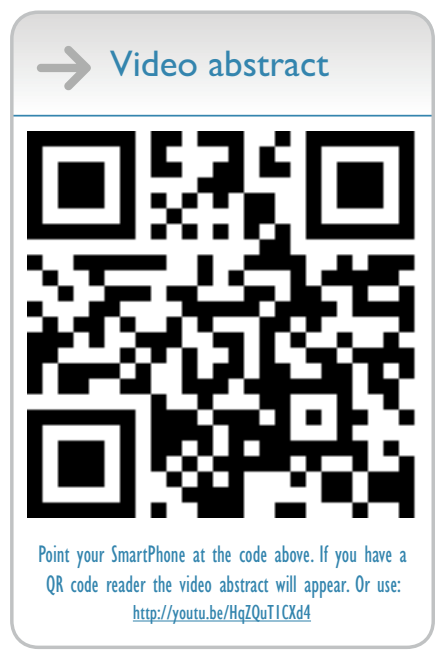

Correspondence: Esther Suter Workforce Research and Evaluation, Alberta Health Services, I030I Southport Lane SW, Calgary T2W IS7, AB, Canada Tel + I 4039430183

Fax + I 4039432875

Email esther.suter@albertahealthservices.ca
Purpose: This study explored which health care providers could be involved in centralized intake for patients with nonspecific low back pain to enhance access, continuity, and appropriateness of care.

Methods: We reviewed the scope of practice regulations for a range of health care providers. We also conducted telephone interviews with 17 individuals representing ten provincial colleges and regulatory bodies to further understand providers' legislated scopes of practice. Activities relevant to triaging and assessing patients with low back pain were mapped against professionals' scope of practice.

Results: Family physicians and nurse practitioners have the most comprehensive scopes and can complete all restricted activities for spine assessment and triage, while the scope of registered nurses and licensed practical nurses are progressively narrower. Chiropractors, occupational therapists, physiotherapists, and athletic therapists are considered experts in musculoskeletal assessments and appear best suited for musculoskeletal specific assessment and triage. Other providers may play a complementary role depending on the individual patient needs.

Conclusion: These findings indicate that an interprofessional assessment and triage team that includes allied health professionals would be a feasible option to create a centralized intake model. Implementation of such teams would require removing barriers that currently prevent providers from delivering on their full scope of practice.

Keywords: scope of practice review, low back pain, integrated service model, centralized intake, interprofessional team

\section{Introduction}

Musculoskeletal conditions are a leading cause of disability and ill health. ${ }^{1}$ In particular, nonspecific low back pain was ranked as the top musculoskeletal disability worldwide in $2010 .^{2}$ The estimated prevalence of back pain in Canada is $\sim 85 \%$, and with a lifetime prevalence approaching $100 \%$, back pain creates unnecessary morbidity and enormous costs to the health care system. . $^{3,4}$

A majority of patients with nonspecific low back pain seek initial help from their primary care physician. ${ }^{5}$ Other frequently consulted health care providers are chiropractors or physical therapists, either through physician referral or self-referral. ${ }^{5}$ However, ill-defined care pathways coupled with inappropriate referrals can result in bottlenecks and lengthy wait times for consultations with spine specialists. ${ }^{6}$ There is also evidence of inappropriate service utilization. A recent Alberta study found that $23 \%-28 \%$ of primary care physicians inappropriately order imaging for back pain and that only $41 \%$ of magnetic resonance imaging requisitions for lumbar spine were 
appropriate. ${ }^{7}$ A minority of patients with nonspecific low back pain are surgical candidates but can be effectively managed by conservative approaches. ${ }^{8}$ Putting patients on surgical wait lists not only delays surgery for patients in need, but patients on wait lists are at risk of developing chronic pain and have poorer clinical outcomes. ${ }^{8-10}$

New service models are being designed to better coordinate care for patients with spine and other musculoskeletal disorders along defined care pathways. Results to date are promising; for example, early clinical triage of musculoskeletal patients has improved patient outcomes and reduced wait times and health care costs. ${ }^{8,11-14}$ In addition, non-physicianled triage systems have been shown to be effective in terms of diagnostic validity, treatment effectiveness, and health care provider and patient satisfaction..$^{8,11,12}$ A triage assessment system was also effective in selecting appropriate care pathways in a large study of patients with low back pain. ${ }^{14}$

Like other countries, Canada is greatly invested in improving access and coordination of care. ${ }^{15}$ The Bone and Joint Health Strategic Clinical Network is a network of researchers, practitioners, planners, and patients in Alberta, Canada, working to transform the way musculoskeletal care is delivered. One important way the Bone and Joint Health Strategic Clinical Network aims to transform the assessment, treatment, and care for people with nonspecific low back pain is by proposing a new interprofessional team-based model of care. The new model should alleviate some of the current issues with back pain care in Alberta such as failure to meet acceptable access times, variation in the process and intensity of clinical care, inappropriate referrals to spine specialties, and ineffective communication and collaboration between back care professionals. Central to the new model is a centralized interprofessional triage and comprehensive assessment system that draws on the knowledge and skills of a range of health care providers.

In order to examine how an interprofessional triage and assessment system could function in Alberta, we conducted an in-depth document review and qualitative assessment of the scope of practice for health care practitioners working with patients with nonspecific low back pain. Specifically, we wanted to evaluate the feasibility of drawing on nonphysician providers for spine care and their potential role in the assessment and triage of spine disorders based on their scope of practice. We aimed to answer the following questions:

1. What type of primary health care providers are involved in assessment, triage, and care planning for nonspecific low back pain and what is their role?

2. What is the scope of practice of these providers?

3. What providers would be most suited for a centralized triage and assessment model?
The findings from the study will inform further the conceptualization of a centralized triage and assessment model for patients with nonspecific low back pain that has the potential to improve access, continuity, and appropriateness of care.

\section{Methods}

\section{Document review}

We identified and retrieved publicly accessible scope of practice regulation documents for the province of Alberta for a range of health care providers involved in the intake and assessment process of patients with nonspecific low back pain. The providers were selected based on feedback from an expert group indicating that these professions are the most commonly sought-after care providers by patients.

The purpose of the document analysis was to identify providers who are able to perform some or all of the different tasks associated with assessment and triaging of patients. ${ }^{16}$ These include performing musculoskeletal assessments, reviewing medical histories, screening for comorbidities, and making referrals to or receiving referrals from other providers. It was also important to establish if providers are authorized to perform the following restricted activities: order or apply X-rays and magnetic resonance imaging; administer diagnostic imaging contrast agents; prescribe medication, dispense or compound medication or sell a drug within the meaning of the provincial Pharmacy and Drug Act.

To ensure that we had a comprehensive list of documents, we identified documents through several means. The first set of documents was identified through our research collaborators. Two researchers (OB and $\mathrm{AB}$ ) searched each of the relevant professional or regulator body websites for documents related to the scope of practice. During interviews, interviewees were asked to provide any further documents they felt would be helpful. We included only legislative documents and documents published by the relevant professional or regulator bodies related to the scope of practice. Organizational and operational documents were excluded.

Two researchers (OB and $\mathrm{AB}$ ) reviewed each document and individually extracted relevant information into an extraction table. The two researchers then reviewed the information together and any disagreement was resolved through discussions.

\section{Interviews}

We used purposive sampling to identify individuals who could speak in detail about the selected providers' scopes of practice and current and potential role in assessment and triage of spine disorders. ${ }^{17}$ Participants were identified through team 
members and by reviewing websites of respective provider colleges. We conducted semistructured telephone interviews with individuals representing ten colleges and regulatory bodies. The interviews lasted 30-60 minutes and were digitally recorded. Each of the participants gave verbal consent which was audio taped prior to the interview.

For the interview analysis, two researchers (OB and $\mathrm{AB})$ listened to the audio recordings and completed written narratives of each interview. The narratives were analyzed using thematic analysis and occurred at a provider level. Thematic analysis is a six-stage process that includes familiarization with data, generating initial codes, searching for themes, reviewing themes, defining and naming themes, and producing a report. ${ }^{18}$ Interviewees were given the opportunity to review and validate the interview analysis to ensure accuracy of interpretation.

This was considered a quality improvement project and did not require approval from the Conjoint Health Research Ethics Board, University of Calgary. Data collection, analysis, and storage complied with the organization's confidentiality and health information policies (Freedom of Information and Protection of Privacy Act).

\section{Results}

We completed 17 interviewees with members from the following ten colleges and associations: Alberta Athletic Therapists Association (1); Alberta College and Association of Chiropractors (1); Alberta College of Paramedics (2); College and Association of Registered Nurses of Alberta (1); College of Alberta Psychologists (1); College of Licensed Practice Nurses of Alberta (3); Alberta College of Occupational Therapists (3); Physiotherapy Alberta College and Association (2); Alberta College of Family Physicians (2); and College of Registered Psychiatric Nurses of Alberta (1). There were three males and 14 females. Interviewees' experience (clinical and managerial) ranged from 7 to 50 years with an average of 26.3 years.

The scope of practice regulation documents for each of these professions were retrieved and reviewed. We integrated the information from the document review and the interviews; highlights are captured in Tables 1 and 2.

\section{Providers best suited to complete an overall initial assessment}

From our document ${ }^{19-32}$ and interview analysis, we found that family physicians, nurse practitioners, registered nurses, licensed practical nurses, and registered psychiatric nurses have a broad skill set that would benefit patients with nonspecific low back pain.
Physicians and all nursing groups in Canada are regulated and adhere to the Health Professions Act. ${ }^{20,23,26,29,31}$ According to our interviewees, the entry level to practice for family physicians, nurse practitioners, and registered nurses is a universitylevel education. Licensed practical nurses and registered psychiatric nurses require a diploma-level education. Registered psychiatric nurses also have the option to voluntarily take postbasic training. Interviewees noted that registered nurses and licensed practical nurses receive broad training and exposure to a range of patient populations. Nurse practitioners receive more thorough training in assessment and pharmacology and have advanced nursing skills and knowledge. Interviewees stated that family physicians receive comprehensive training, including how to evaluate and manage spine disorders. They further stated that all providers are expected to complete continuing competency development on an annual basis. Registered psychiatric nurses can voluntarily take post-basic training.

Based on our interview and document analysis, ${ }^{19-32}$ these five provider groups appear most suited to complete an initial holistic assessment for patients with nonspecific low back pain. This may include an assessment of medical history, comorbidities, ${ }^{19,24,25,27}$ psychosocial issues, and lifestyle factors. Only family physicians and nurse practitioners are able to make referrals to specialist providers. ${ }^{19,24}$ Interviewees reported that a registered nurse is able to make referrals but only to a nurse practitioner or a family physician, while a registered psychiatric nurse can only make referrals to a psychiatrist. With respect to restricted activities for spine-related issues, family physicians and nurse practitioners have the broadest scope..$^{19,20,23,24}$ Licensed practical nurses and registered psychiatric nurses are limited in the restricted activities they are authorized to perform, ${ }^{27-32}$ but they can refer to a physician as needed. Interviewees pointed out that nurse practitioners and registered nurses practicing to full scope may be limited by the employer and care model context. Family physicians may self-restrict their scope based on skill and area of interest.

\section{Providers best suited to complete musculoskeletal assessment and triage}

Our interview and document review data ${ }^{33-46}$ would suggest that chiropractors, occupational therapists, physiotherapists, and athletic therapists were identified as providers best suited to complete musculoskeletal assessment and triage (Table 1). Interviewees noted that these providers' initial education is grounded in movement science, providing them with the necessary skills to conduct thorough musculoskeletal assessments. With the exception of athletic therapists, these providers are regulated in Alberta. Interviewees reported that the entry level to practice requirement for an occupational 


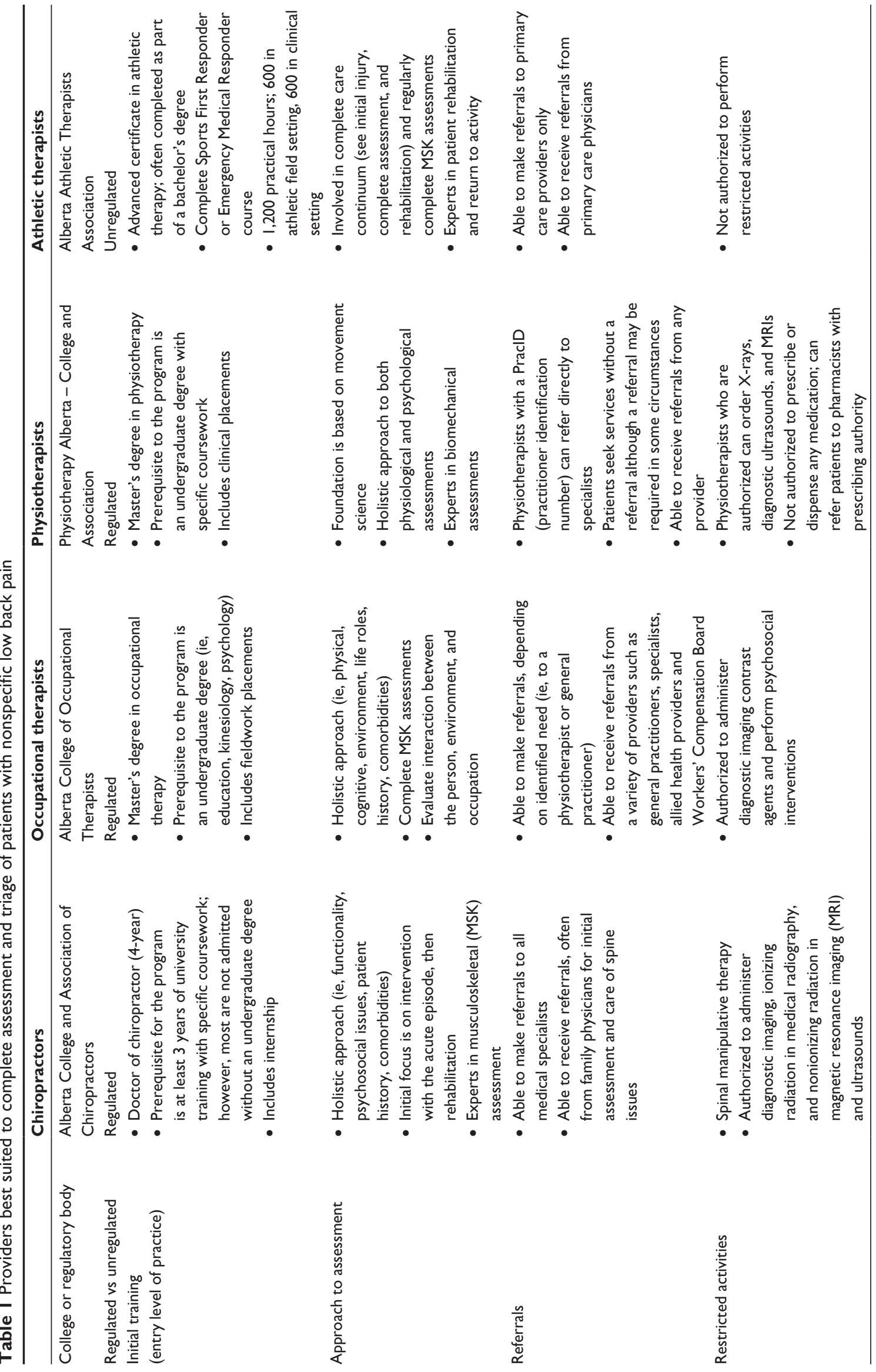




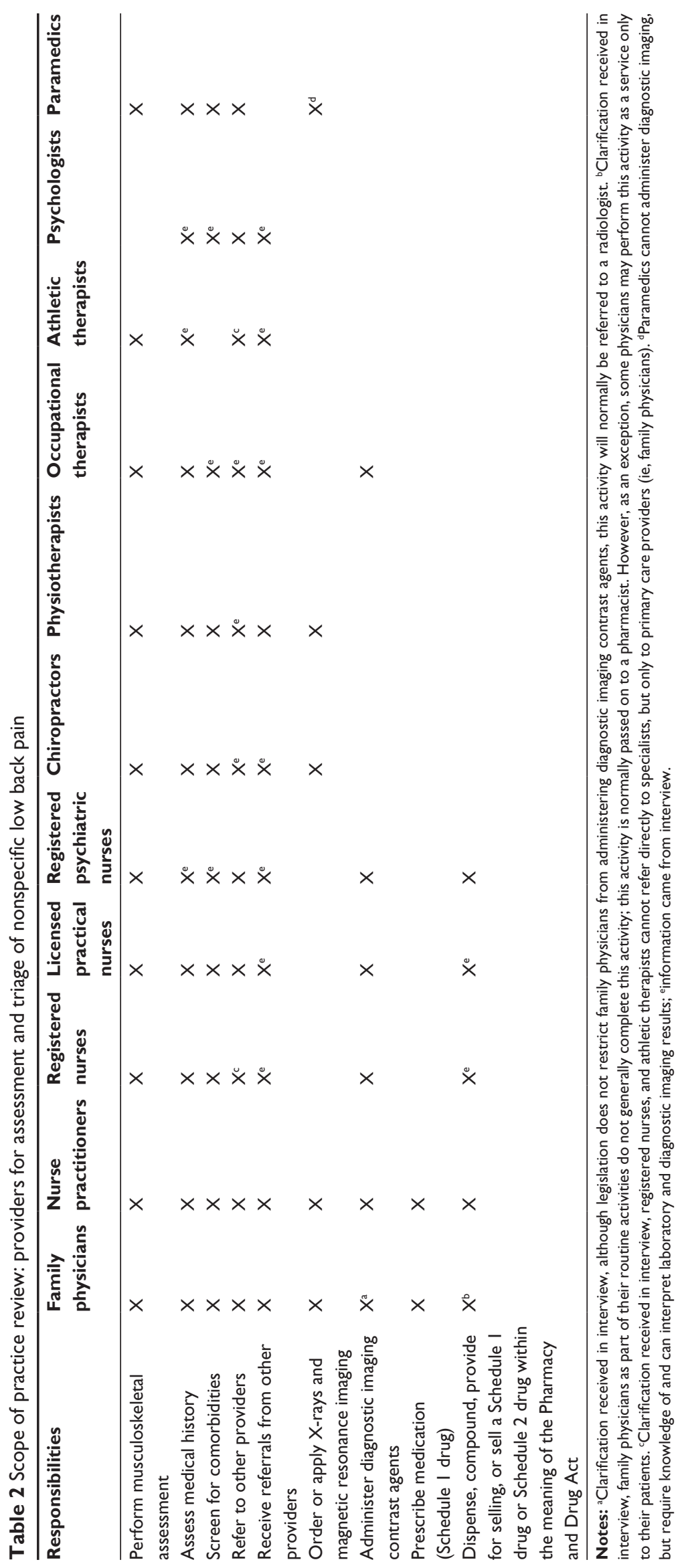


therapist or physiotherapist is a master's degree, and to practice as a chiropractor, a doctoral degree is required. Athletic therapists require an advanced certificate to practice. Each of the providers is expected to commit to ongoing professional development. Chiropractors and athletic therapists have a specific number of continuing education credits they must complete each year. Occupational therapists and physiotherapists pursue competencies in any area of interest and of benefit to their practice setting.

All four providers have expertise in musculoskeletal assessments, intervention, and patient rehabilitation. Interviewees noted that for all four providers, assessment extends beyond physical examination and includes psychosocial and functional issues, and the review of patients' medical histories. Apart from athletic therapists, the providers routinely screen for comorbidities. Interviewees pointed out that although athletic therapists have the skills to screen for underlying comorbidities, this is not part of their routine assessment.

Our review of the scope of practice documents ${ }^{38,43}$ and interview data revealed that all four provider groups can receive referrals from primary care providers for initial assessments. According to interviewees, of the four providers, only chiropractors and physiotherapists can make direct referrals to specialists. Occupational therapists can make referrals ${ }^{39}$ but only to other primary care providers, while athletic therapists can only refer to family physicians. None of the four providers are authorized to perform all the listed restricted activities but most are authorized to perform at least one activity (Table 1$){ }^{33-46}$

Interviewees identified several obstacles resulting from legislations, policies, and lack of awareness of providers' skills and knowledge as factors limiting providers from working to full scope. For example, some practitioners are unaware of how occupational and athletic therapists can contribute to a patient's continuum of care, resulting in underutilization of these two groups. As well, although it is within the scope of practice of chiropractors to perform lab tests, reimbursement policies do not allow them to perform this activity. Lastly, while physiotherapists in the public sector have access to Netcare (Alberta's most common electronic medical record), those in the private sector do not. Having to request patients' medical records increases the wait to complete initial assessment.

\section{Providers best suited for a complementary role}

Paramedics and psychologists could play a complementary role for spine assessment and triage. Both are regulated providers.
From our interview analysis, we noted that paramedics and psychologists take different approaches when assessing patients with nonspecific low back pain. The focal point of a psychologist's assessment is to identify psychological disorders, while paramedics conduct physical assessments with a focus on appropriate mobilization of patients. Both providers review medical histories and screen for comorbidities. However, paramedics screen for physical disorders, whereas the psychologists look for underlying issues such as anxiety, depression, anger, and hopelessness. Paramedics and psychologists are not authorized to perform any of the listed restricted activities. ${ }^{47-55}$

Interviewees consistently noted that providers from all the ten disciplines mentioned would require appropriate training on assessment protocols and criteria to ensure consistency in triaging and assessing patients. Participants further noted that on-the-job training and experience in a content area is invaluable to completing their roles and that new graduates from various professions would likely not have the experience necessary to fulfill roles specific to spine assessment and triage.

Table 2 summarizes the scopes for the different professions relevant to spine disorders.

\section{Discussion}

This is a timely review as there is increased demand for interprofessional teams in the health care system to increase continuity and appropriateness of care. ${ }^{15,56}$

Current data suggest that most low back pain is inappropriately triaged and referred, leading to poor continuity of care and potentially poorer outcomes for patients due to delayed treatment. ${ }^{7}$ Previous research has demonstrated the effectiveness of nonphysician-led triage systems for musculoskeletal disorders. ${ }^{8,11,12}$ Our scope of practice review and qualitative interview findings indicate that an interprofessional triage-based system is feasible within the Alberta context and that providers from various disciplines bring different perspectives and abilities to the assessment based on their professional philosophies and training.

We found that family physicians and nurse practitioners have the most comprehensive scope and can complete all responsibilities for spine assessment and triage. ${ }^{19,20,22-26}$ Registered nurses and licensed practical nurses have some limitations for restricted activities and referrals. ${ }^{23-25,27,29}$ A physiotherapist, a chiropractor, or an occupational therapist can fulfill many of the responsibilities associated with spine assessment and triage but have limitations for prescribing and dispensing medications. ${ }^{33-43}$ They appear best suited 
for musculoskeletal specific triage and assessment as these providers are well trained and considered experts in this area. Although athletic therapists are unregulated, they would be able to execute care plans and provide rehabilitation.

Generally, the scope of the remaining providers (registered psychiatric nurses, psychologists, paramedics, athletic therapists) is narrower, but they still have the ability to contribute in many ways to spine assessment and triage. Psychologists and paramedics could add complementary services and support depending on individual patient needs. Studies show that back pain and psychological distress are highly correlated ${ }^{57}$ and that appropriate assessment for psychological "yellow" flags leads to more positive results. ${ }^{58}$

There is evidence suggesting that interprofessional approaches to chronic conditions improve patient outcomes and patient and provider satisfaction. ${ }^{6,59-60}$ These improvements have been attributed to having the most appropriate care providers with the greatest expertise delivering care. ${ }^{61}$ It has also been argued that early engagement of musculoskeletal specialists would result in more evidence-based and consistent management of musculoskeletal disorders with the potential for better clinical outcomes and secondary prevention. ${ }^{5}$ Drawing on health professionals considered experts in musculoskeletal assessments can help reduce the burden on primary care physicians to triage patients with nonspecific low back pain toward appropriate care.

Our study has a number of limitations. We covered a broad range of musculoskeletal care providers; however, there are others who care for patients with nonspecific low back pain, such as massage therapists, psychiatrists, and acupuncturists who were not examined here. Since scope of practice regulation differs across countries, suitability of certain provider types will vary based on local context. It is also important to note that each discipline will likely bring different perspectives and skills to the assessment and triage of patients based on professional philosophies and training and experience; this has not been investigated in this study. When establishing an interprofessional model for spine assessment and triage, it has been recommended that providers may require additional education and mentorship relating to specific aspects of care and that their performance needs to be critically evaluated. ${ }^{5}$

Despite the potential benefits of interprofessional collaborative care teams, it is important to further research on how to implement and use these teams effectively. There are systems barriers, such as payment models, lack of space, and professional prejudices, that prevent successful integration. ${ }^{62}$ Some practitioners may need their scope of practice expanded to perform certain activities to facilitate assessment and triage. For example, physiotherapists in Alberta are currently not approved to order lab tests which are crucial to confirm diagnosis for some patients. Lastly, it will be essential to research on how we can develop a shared philosophy, role clarity, and an agreed-upon care pathway so providers can work together effectively.

\section{Conclusion}

This study demonstrates how a careful review of scopes of practice and role requirements can inform the development of new service delivery arrangements that have the potential to improve continuity of care. Specifically, it can open the dialogue for including health providers not commonly considered as members of an interprofessional team, such as chiropractors.

Our analysis of musculoskeletal providers' scope of practice points to the feasibility of a non-physician-led interprofessional low back pain triage and assessment team of health professionals. In order to successfully implement such a team, the barriers identified that prevent providers from practicing to their full scope must be addressed. As noted by our interviewees, the importance of continued education and experience, as well as role clarity and a shared philosophy, must also be considered to ensure appropriate and efficient care for musculoskeletal patients.

\section{Acknowledgments}

We would like to thank all our invited colleges and associations for their participation. We would also like to thank members of the Bone and Joint Health Strategic Clinical Network for their valuable input throughout the study. This project was conducted within the broader context of the SpineAccess Alberta project of the Bone and Joint Health Strategic Clinical Network. Spine Access Alberta was funded by Alberta Innovates - Health Solution, Partnership for Research Innovation in the Health System (PRIHS) fund; Principal Investigator Dr Linda Woodhouse and Co-Principal Investigators Drs Greg Kawchuk and Leah Phillips.

\section{Disclosure}

The authors report no conflicts of interest in this work.

\section{References}

1. CIHR IRSC. Institute of Musculoskeletal Health and Arthritis, Strategic Plan 2014-2018: Enhancing Musculoskeletal, Skin and Oral Health. Her Majesty the Queen in Right of Canada; Ottawa, 2014. Cat No: MR4-35/2014E-PDF. 
2. Vos T, Flaxman AD, Naghavi M, et al. Years lived with disability (YLDs) for 1160 sequelae of 289 diseases and injuries 1990-2010: a systematic analysis for the Global Burden of Disease Study 2010. Lancet. 2012;380(9859):2163-2196.

3. Carroll LJ, Cassidy JD, Côté P. The Saskatchewan health and back pain survey: the prevalence of low back pain and related disability in Saskatchewan adults. Spine J. 1998;23(17):1860-1866; discussion 1867.

4. Dagenais S, Caro J, Haldeman S. A systematic review of low back pain cost of illness studies in the United States and internationally. Spine J. 2008;8(1):8-20.

5. Foster NE, Hartvigsen J, Croft PR. Taking responsibility for the early assessment and treatment of patients with musculoskeletal pain: a review and critical analysis. Arthritis Res Ther. 2012;14:205.

6. Maddison P, Jones J, Breslin A, et al. Improved access and targeting of musculoskeletal services in northwest Wales: targeted early access to musculoskeletal services (TEAMS) programme. $B M J$. 2004;329(7478):1325-1327.

7. Emery D, Shojania KG, Forster AJ, Mojaverien N, Feasby TE. Overuse of magnetic resonance imaging. JAMA Intern Med. 2013;173(9):823-825.

8. Bath B, Janzen B. Patient and referring health care provider satisfaction with a physiotherapy spinal triage assessment service. J Multidiscip Healthc. 2012;5:1-15.

9. Silverplats K, Lind B, Zoëga B, et al. Clinical factors of importance for outcome after lumbar disc herniation surgery: long-term follow-up. Eur Spine J. 2010;19(9):1459-1467.

10. Valat JP, Goupille P. Védere V. Low back pain: risk factors for chronicity. Rev Rhum Engl Ed. 1997;64(3):189-194.

11. Kennedy DM, Robarts S, Woodhouse LJ. Patients are satisfied with advanced practice physiotherapists in a role traditionally performed by orthopaedic surgeons. Physiother Can. 2010;62(4): 298-305.

12. Desmeules F, Roy J, MacDermid JC, Champagne F, Hinse O, Woodhouse LJ. Advanced practice physiotherapy in patients with musculoskeletal disorders: a systematic review. BMC Musculoskelet Disord. 2012;13:107.

13. Stanhope J, Grimmer-Somers K, Milanese S, Kumar S, Morris J. Extended scope physiotherapy roles for orthopedic outpatients: an update systematic review of the literature. J Multidiscip Healthc. 2012;5:37-45.

14. Murphy S, Blake C, Power CK, Fullen BM. The role of clinical specialist physiotherapists in the management of low back pain in a spinal triage clinic. Ir J Med Sci. 2013;182(4):643-650.

15. Bichel A, Erfle S, Wiebe V, Axelrod D, Conly J. Improving patient access to medical services: preventing the patient from being lost in translation. Healthc Q. 2009;13 Spec No:61-68.

16. Suter E, Birney A, Charland P, et al. Optimizing the interprofessional workforce for centralized intake of patients with osteoarthritis and rheumatoid disease: case study. Hum Resour Health. 2015; 13:41.

17. Tongco MD. Purposive sampling as a tool for informant selection. Ethnobot Res Appl. 2007;5:147-158.

18. Braun V, Clarke V. Using thematic analysis in psychology. Qual Res Psychol. 2006;3(2):77-101.

19. College of Physicians and Surgeons of Alberta. Standards of practice. 2011. Available from: http://www.cpsa.ab.ca/Libraries/Res_Standards_ of_Practice/CPSA_Standards_of_Practice_Consolidated_Version.pdf. Accessed March 15, 2016.

20. Province of Alberta. Health Professions Act: Physicians, surgeons and osteopaths profession regulation. 2009. Available from: http://www. qp.alberta.ca/documents/Regs/2009_350.pdf. Accessed March 15, 2016.

21. Canadian Medical Association. Canadian Medical Association code of ethics. 2004. Available from: http://policybase.cma.ca/dbtw-wpd/ PolicyPDF/PD04-06.pdf. Accessed March 15, 2016.
22. Province of Alberta. Health Profession Act: Schedule 21 - Profession of physicians, surgeons and osteopaths practice statement: 245-261. 2015. Available from: http://www.qp.alberta.ca/documents/Acts/h07. pdf. Accessed March 15, 2016.

23. College and Association of Registered Nurses of Alberta. Health Professions Act: Standards for registered nurses in the performance of restricted activities. 2005. Available from: http://www.nurses.ab.ca/ content/dam/carna/pdfs/DocumentList/Standards/HPA_RestrictedActivities_Oct2005.pdf. Accessed March 15, 2016.

24. College and Association of Registered Nurses of Alberta. Nurse practitioner (NP) competencies. 2011. Available from: http://www. nurses.ab.ca/content/dam/carna/pdfs/DocumentList/Standards/ NP_Competencies_Jan2011.pdf. Accessed March 15, 2016.

25. College and Association of Registered Nurses of Alberta. Entry to practice competencies for the registered nurses profession. 2013. Available from: http://www.nurses.ab.ca/content/dam/carna/pdfs/ DocumentList/Standards/RN_EntryPracticeCompetencies_May2013. pdf. Accessed March 15, 2016.

26. Province of Alberta. Health Professions Act: Registered nurses profession regulation. 2005. Available from: http://www.qp.alberta.ca/1266. cfm?page $=2005 \_232$.cfm\&leg_type $=$ Regs\&isbncln $=0779741986$. Accessed March 15, 2016.

27. College of Licensed Practical Nurses of Alberta and Alberta Health and Wellness. Competency profile for licensed practical nurses of Alberta, 2nd ed. 2005. Available from: http://www.clpna.com/wp-content/ uploads/2013/02/doc_AB_LPN_Competency_Profile_2nd\%20Edition. pdf. Accessed March 15, 2016.

28. College of Licensed Practical Nurses of Alberta. Code of ethics and standards of practice. 2008. Available from: http://www.clpna.com/wpcontent/uploads/2013/02/doc_CLPNAEthics-Standards.pdf. Accessed March 15, 2016.

29. Province of Alberta. Health Professions Act: Licensed practical nurses profession regulation. 2003. Available from: http://www.qp.alberta.ca/ documents/Regs/2003_081.pdf. Accessed March 15, 2016.

30. Province of Alberta. Health Professions Act: Schedule 10-Profession of licensed practical nurses practice statement: 171-177. 2015. Available from: http://www.qp.alberta.ca/documents/Acts/h07.pdf. Accessed March 15, 2016.

31. Province of Alberta. Health Professions Act: Registered psychiatric and mental deficiency nurses profession regulation. 2005. Available from: http://www.qp.alberta.ca/documents/Regs/2005_231.pdf. Accessed March 15, 2016.

32. College of Registered Psychiatric Nurses of Alberta. Code of ethics and standards of psychiatric nursing practice. 2010. Available from: http:// www.crpnbc.ca/wp-content/uploads/2011/02/2010_Code_Standards. pdf. Accessed March 15, 2016.

33. Alberta College and Association of Chiropractors. Standards of practice. 2011. Available from: http://www.albertachiro.com/ieadmin/files/ ACAC_Standards_of_Practice.pdf. Accessed March 15, 2016.

34. Alberta College and Association of Chiropractors. Code of ethics. 2012. Available from: http://www.albertachiro.com/ieadmin/files/ Code_of_Ethics.pdf. Accessed March 15, 2016.

35. Province of Alberta. Health Professions Act-Chiropractors profession regulation. 2006. Available from: http://www.qp.alberta.ca/documents/ Regs/2006_277.pdf. Accessed March 15, 2016.

36. Province of Alberta. Health Professions Act-Occupational therapists profession regulation. 2006. Available from: http://www.qp.alberta.ca/ documents/Regs/2006_217.pdf. Accessed March 15, 2016.

37. Alberta College of Occupational Therapists. Code of ethics. 2005. Available from: http://acot.ca/wp-content/uploads/2015/09/Code_of_ Ethics.pdf. Accessed March 15, 2016

38. Association of Canadian Occupational Therapy Regulatory Organizations. Essential competencies of practice for occupational therapists in Canada, 3rd ed. 2012. Available from: http://acotro-acore. org/sites/default/files/uploads/ACOTRO_EC_3rd_ed.pdf. Accessed March 15, 2016. 
39. Alberta College of Occupational Therapists. Standards of practice. 2003. Available from: http://acot.ca/wp-content/uploads/2016/01/Standardsof-Practice.pdf. Accessed March 15, 2016.

40. Province of Alberta. Health Professions Act: Physical therapists profession regulation. 2011. Available from: http://www.qp.alberta.ca/ documents/Regs/2011_064.pdf. Accessed March 15, 2016.

41. Province of Alberta. Health Professions Act: Schedule 20-Profession of physical therapists practice statement: 235-244. 2015. Available from: http://www.qp.alberta.ca/documents/Acts/h07.pdf. Accessed March 15, 2016.

42. National Physiotherapy Advisory Group. Essential competency profile for physiotherapists in Canada. 2009. Available from: http://www. physiotherapyeducation.ca/Resources/Essential\%20Comp\%20PT\%20 Profile\%202009.pdf. Accessed March 15, 2016.

43. Physiotherapy Alberta - College + Association. Standards of practice for Alberta physiotherapists. 2012. Available from: https://www. physiotherapyalberta.ca/files/practice_standards_all_2012_revised.pdf. Accessed March 15, 2016.

44. Physiotherapy Alberta-College + Association. Code of ethics. Available from: https://www.physiotherapyalberta.ca/files/code_of_ethics.pdf. Accessed March 15, 2016.

45. Canadian Athletic Therapists Association. Code of ethics and code of conduct. Available from: http://www.athletictherapy.org/en/code_of_ ethics.aspx. Accessed March 15, 2016.

46. Canadian Athletic Therapists Association. Scope of practice. Available from: http://www.athletictherapy.org/en/scope_of_practice.aspx. Accessed March 15, 2016.

47. Alberta College of Paramedics. Continuing competency profile Emergency medical responder (EMR). 2005. Available from: https:// www.collegeofparamedics.org/media/66516/aocp_emr_full.pdf. Accessed March 15, 2016.

48. Alberta College of Paramedics. Continuing competency profile Emergency medical technician (EMT). 2005. Available from: https:// www.collegeofparamedics.org/media/66519/aocp_emt_full.pdf. Accessed March 15, 2016.

49. Alberta College of Paramedics. Continuing competency profile Emergency medical technologist-paramedic (EMT-P). 2005. Available from: https://www.collegeofparamedics.org/media/66522/aocp_emtp_ full.pdf. Accessed March 15, 2016.

50. Alberta College of Paramedics. Code of ethics and standards of practice. Available from: https://www.collegeofparamedics.org/media/9839/ codeofethics.pdf. Accessed March 15, 2016.
51. Province of Alberta. Health Disciplines Act: Emergency medical technicians regulation. 2007. Available from: http://www.qp.alberta. ca/documents/Regs/1993_048.pdf. Accessed March 15, 2016.

52. Canadian Psychological Association. Canadian code of ethics for psychologists, 3rd ed. 2000. Available from: http:/www.cpa.ca/docs/ File/Ethics/cpa_code_2000_eng_jp_jan2014.pdf. Accessed March 15, 2016.

53. College of Alberta Psychologists. Practice Guideline: Self-regulation in the profession of psychology. 2008. Available from: http://www.cap. ab.ca/pdfs/Self-RegulationInTheProfessionOfPsychologySept2014.pdf. Accessed March 15, 2016.

54. College of Alberta Psychologists. Standards of practice. 2013. Available from: http://www.cap.ab.ca/pdfs/HPAStandardsofPractice. pdf?v20160307163658. Accessed March 15, 2016.

55. Province of Alberta. Health Professions Act: Psychologists profession regulation. 2005. Available from: http://www.qp.alberta.ca/documents/ Regs/2005_251.pdf. Accessed March 15, 2016.

56. Nelson S, Turnbull J, Bainbridge L, et al. Optimizing Scopes of Practice: New Models for a New Health Care System. Ottawa, ON: Canadian Academy of Health Sciences; 2014.

57. Pinheiro MB, Ferreira ML, Refshauge K, et al. Symptoms of depression and risk of new episodes of low back pain. A systematic review and meta-analysis. Arthritis Care Res (Hoboken). 2015;(11):1591-1603.

58. Nicholas MK, Linton SJ, Watson PJ, Main CJ; "Decades of the Flags" Working Group. Early identification and management of psychological risk factors ("yellow flags") in patients with low back pain: a reappraisal. Phys Ther. 2011;91(5):737-753.

59. Garner MJ, Birmingham M, Aker P, et al. Developing integrative primary healthcare delivery: adding a chiropractor to the team. Explore (NY) 2008;4(1):18-24.

60. Kopansky-Giles D, Vernon H, Boon H, Steinman I, Kelly M, Kachan N Inclusion of a CAM therapy (chiropractic care) for the management of musculoskeletal pain in an integrative, inner city, hospital-based primary care setting. J Alter Med Res. 2010;2(1):61-74.

61. Goldman J, Meuser J, Rogers J, Lawrie L, Reeves S. Interprofessional collaboration in family health teams: an Ontario-based study. Can Fam Physician. 2010;56(10):e368-e374.

62. Chung CL, Manga J, McGregor M, Michailidies C, Stavros D, Woodhouse L. Interprofessional collaboration and turf wars. How prevalent are hidden attitudes? J Chiropr Educ. 2012;26(1):32-39.
Journal of Multidisciplinary Healthcare

\section{Publish your work in this journal}

The Journal of Multidisciplinary Healthcare is an international, peerreviewed open-access journal that aims to represent and publish research in healthcare areas delivered by practitioners of different disciplines. This includes studies and reviews conducted by multidisciplinary teams as well as research which evaluates the results or conduct of such teams or

\section{Dovepress}

healthcare processes in general. The journal covers a wide range of areas and welcomes submissions from practitioners at all levels, from all over the world. The manuscript management system is completely online and includes a very quick and fair peer-review system. Visit http://www.dovepress.com/testimonials.php to read real quotes from published authors. 